BULLETIN Bulletin hispanique

HISPANIQUE Université Michel de Montaigne Bordeaux

112-1| 2010

Actes du Colloque « langue, littérature, littéralité »

\title{
Fernanda Macchi, Incas ilustrados. Reconstrucciones imperiales en la segunda mitad del siglo XVIII
}

Vervuert-Iberoamericana, Madrid, Frankfurt, 2009

Isabelle Tauzin-Castellanos

\section{CpenEdition}

\section{Journals}

Edición electrónica

URL: http://journals.openedition.org/bulletinhispanique/1200

DOI: 10.4000/bulletinhispanique.1200

ISSN: 1775-3821

\section{Editor}

Presses universitaires de Bordeaux

Edición impresa

Fecha de publicación: 1 junio 2010

Paginación: 445-448

ISBN: 978-2-86781-692-5

ISSN: 0007-4640

Referencia electrónica

Isabelle Tauzin-Castellanos, "Fernanda Macchi, Incas ilustrados. Reconstrucciones imperiales en la segunda mitad del siglo XVIII », Bulletin hispanique [En línea], 112-1 | 2010, Publicado el 04 enero 2013, consultado el 23 septiembre 2020. URL : http://journals.openedition.org/bulletinhispanique/1200 ; DOI : https://doi.org/10.4000/bulletinhispanique.1200 
ce que pour leur caractère stimulant, tant pour les spécialistes de littérature que pour les historiens, qui pourront mesurer à travers le prisme littéraire l'importance de phénomènes dont ils ne sont pas toujours conscients.

Jean-Pierre DEDIEU

Fernanda Macchi, Incas ilustrados. Reconstrucciones imperiales en la segunda mitad del siglo XVIII, Madrid, Frankfurt, Vervuert-Iberoamericana, 2009, 286 p.

Incas ilustrados. Reconstrucciones imperiales en la segunda mitad del siglo XVIII est un ouvrage multiple comme l'indique le titre choisi par Fernanda Macchi. Elle analyse d'abord les rééditions et les traductions de l'œuvre de l'inca Garcilaso de la Vega, puis des écrits parus au XVIII' siècle évoquant l'ancien empire. D'origine argentine, Macchi est professeur à l'Université Mac Gill (Montréal) ; le corpus sur lequel porte son analyse est plurilingue (espagnol, français et anglais).

Garcilaso de la Vega, fils d'un conquérant et d'une princesse inca, partit en Espagne en 1560 pour revendiquer son héritage ; il vécut en Andalousie jusqu'à sa mort en 1616. La première partie de ses Commentaires royaux, recréant l'univers inca soixante ans après l'arrivée de Pizarre (1532), parut à Lisbonne en 1609, tandis que l'Histoire générale du Pérou, la deuxième partie des Commentaires consacrée à l'étape de la conquête et aux guerres intestines, fut éditée en 1617.

Fernanda Macchi relève un difficile pari : démontrer comment l'œuvre centrale de l'inca a été altérée au fil des éditions, soumise à une infinité de manipulations idéologiques, indécelables par le lecteur non spécialiste. Elle observe que le renouvellement des études coloniales, notamment grâce à la rigueur de chercheurs latino-américains (Mazzotti, García Bedoya, ChangRodriguez...), est méconnu au-delà des universités américaines, tandis que des travaux conçus sur la base de traductions anglaises et françaises ignorant l'histoire textuelle des Commentaires ont bénéficié d'une diffusion excessive. C'est contre cette manipulation des sources que s'insurge l'auteur d'Incas ilustrados en signalant: " ese tipo de lectura reproduce inconscientemente una lógica colonial » (86).

Après l'édition princeps, il fallut attendre plus d'un siècle, jusqu'en 1722 pour que les œuvres de Garcilaso paraissent à Madrid, sous l'autorité d'Andrés González de Barcia, dont Macchi s'attache à rappeler l'itinéraire dans la république des lettres de la première moitié du XVIII siècle. Barcia exerça de nombreuses missions au service de Philippe $V$ et prit part à la 
fondation de la Real Academia. Au moment de publier l'œuvre de Garcilaso, Barcia ne choisit pas l'ordre chronologique de parution mais donne la priorité à l'Histoire générale du Pérou. De la sorte, il privilégie l'héritage espagnol, laissant dans l'ombre la filiation indienne. L'étape des guerres civiles prévaut ainsi dans la représentation du Pérou.

En 1722 Barcia réédite aussi l' Histoire de la Floride, un texte de Garcilaso de 1605 qui est instrumentalisé pour contester les dénonciations de Bartolomé de las Casas, accusé par l'éditeur castillan d' "ignorancia y desidia ". En ce début de XVIII siècle, il s'agit de défendre un territoire menacé par les visées expansionnistes des Anglais et des Français en valorisant la Floride de Garcilaso comme un texte d'histoire justifiant l'appropriation de l'espace nord-américain en litige.

La première partie des Commentaires royaux est publiée, un an plus tard, en 1723, avec un prologue de Barcia. L'éditeur insiste sur le rôle de la Couronne dans la Conquête du Pérou et prétend compléter l'œuvre de Garcilaso par l'inclusion d'autres voix (Honorius Philoponus et Calancha) de façon à légitimer l'entreprise de conquête et gommer les critiques de Garcilaso à l'égard du gouvernement du vice-roi Toledo. Macchi commente ce détournement du texte: "El gesto nostálgico de Barcia busca la reconstrucción de la historia imperial para cimentar un acto de reapropiación no sólo simbólico sino también real del territorio. Barcia concibe 'sus' crónicas como armas contra la envidia extranjera que gesta inapropiadas versiones que pasan a los pueblos indios" (84).

L'auteur de Incas ilustrados s'intéresse ensuite dans une deuxième partie aux traductions de l'œuvre garcilasienne. Fernanda Macchi rappelle que Garcilaso, né au Cuzco et de langue maternelle quechua, se fit d'abord connaître en traduisant les Dialogues d'amour de Léon L'Hébreu, bilingue lui aussi et installé à Gênes après l'expulsion de 1492. Les traducteurs français ont en fait adapté les Commentaires royaux en usant de multiples procédés que le volume met en évidence. La classification générique choisie par Garcilaso avec le mot " commentaires " a été supprimée dès la traduction de Jean Baudoin (1633), suppression qui transforme ces essais interprétatifs sur le Pérou en histoire des incas et en miroir des princes. Le lecteur croit ainsi reconnaître dans l'ancien empire un modèle de gouvernement digne d'imitation.

La traduction posthume n'est pas littérale, mais complétée par des connecteurs et des italiques. La polyphonie du texte originel est oblitérée par la distinction visuelle des voix indiennes et espagnoles et le remplacement des tournures impersonnelles par un sujet de l'énonciation. L'édition parue à Amsterdam en 1704 renforcera encore le sujet de l'énonciation par 
l'adjonction de guillemets et de vocabulaire évaluatif, tandis que des notes en bas de page extraites parfois du corps du texte et la suppression de passages que le traducteur considère redondants, rapprocheront les Commentaires de l'écrit historique monologique. Les éditions suivantes $(1715,1737)$ sont complétées par des illustrations qui présentent un Indien «irreconocible en su construido exotismo [...], desnudo, desprovisto y maravillado en su conciencia." (115). Une nouvelle Histoire des Incas paraît en France en 1744, agrémentée de nombreuses références aux voyageurs du siècle (Frézier, La Condamine, Feuillée), dénaturant les Commentaires en réorganisant la temporalité et en supprimant ce qui est le moins compréhensible au lecteur européen. L'empire inca semble un idéal à imiter par l'Europe tandis que le pouvoir de Louis XV apparaît discrédité et les richesses américaines dilapidées par la Couronne espagnole.

Des manipulations similaires ont été opérées dans les traductions anglaises, selon Fernanda Macchi et le texte de Garcilaso est devenu prétexte : "Operación básica del moderno eurocentrismo, el viaje del siglo xviii ingresó en el cuadro de las cosas el horizonte colonial materializando una nueva conquista puramente simbólica" (126).

De la traduction à la fiction, le pas de la transformation générique est franchi avec Les mille et une heures, contes péruviens de Thomas Simon Gueulette (1733), Alzire de Voltaire (1736) et le roman épistolaire de Madame de Graffigny Lettres d'une Péruvienne (1747). Ces fantaisies impériales, qui s'approprient l'œuvre de Garcilaso parfois sans la mentionner, valorisent les incas et, par voie de conséquence, condamnent les puissants français et espagnols. Les Lettres ont particulièrement intéressé F. Macchi qui, même si elle n'a pas eu à sa disposition la bibliographie française la plus récente sur Graffigny et Gueulette, observe la reconstruction d'une voix indigène dans ces best-sellers du XVIII ${ }^{\mathrm{e}}$ siècle.

Macchi aurait pu développer cette partie avec d'autres ouvrages comme Les Incas de Marmontel (1777), mais elle reste fidèle au cadre chronologique de la première moitié du XVIII ${ }^{\mathrm{e}}$ siècle, moment des rééditions des Commentaires de Garcilaso.

L'empire inca a aussi été source d'inspiration pour les Péruviens. Pedro de Peralta (1693-1743), polygraphe baroque, défenseur de Pizarre dans Lima fundada (1732), a remémoré dans Júbilos de Lima y Fiestas Reales (1723) un empire modèle de justice et de bonne administration. La description des festivités en l'honneur des princes européens est aussi l'occasion de dépeindre l'état apparent de concorde entre les trois nations espagnole, indienne et noire, comme l'a signalé Juan Carlos Estenssorro (2005). Mais l'ordre ne doit pas être altéré dans cet hommage solennel à la monarchie ; 
F. Macchi souligne que, si l'accession des caciques à des charges jusque-là réservées aux créoles est une preuve de l'ouverture du régime, un bataillon d'Indiens vêtus à l'espagnole évite le tumulte de la foule et empêche que le public ne confonde la scénographie de la puissance ancienne et la ségrégation de l'époque moderne. La chercheuse complète son travail sur les reconstructions impériales en évoquant le drame inca Ollantay dont la datation est encore l'objet de débats. Elle reprend l'analyse de Martin Lienhard définissant l'Ollantay comme "expresión del predominio de la cultura oficial y la resistencia de unas culturas autóctonas marginadas que se nutren tanto de su pasado autónomo como de su historia en el marco colonial o semicolonial "(257). Comme pour les Lettres d'une Péruvienne, Macchi est attentive à la mise en scène de l'enfermement féminin et interprète la résolution de l'intrigue comme l'allégorie d'un futur modèle de communion sociale, dans le prolongement de la renaissance inca théorisée par John Rowe en 1954.

L'ouvrage de Fernanda Macchi s'achève sur l'Indépendance et la revendication de l'héritage inca lors du Congrès de Tucuman scellant la naissance des Provinces Unies du Rio de la Plata (1816), un saut chronologique et spatial qui explique peut-être la référence du titre à la seconde moitié du XVIII ${ }^{\mathrm{e}}$ siècle, postérieure à l'ensemble des " reconstructions impériales ", objets de cette étude hardie et minutieuse, mais qui prudemment n'aspire pas à l'exhaustivité sur un sujet encyclopédique.

\section{Isabelle TAUZIN-CASTELLANOS}

Rafael Alarcón Sierra, El mal poema de Manuel Machado:Una lírica moderna y dialógica. - Madrid, Editorial Biblioteca Nueva, 2008, 311 p. (Estudios críticos de literatura, 32) : índice onomástico. - ISBN 978-849742-748-7.

Rafael Alarcón Sierra es especialista principal en la obra de Manuel Machado. Es autor de numerosos artículos y de distintos estudios y ediciones cuya solvencia la garantiza siempre un amplio bagaje lector, que no se circunscribe únicamente a la tradición española, y una documentación de máxima especialización filológica. Sus monografías más relevantes sobre este tema son La poesía de Manuel Machado: Alma, Caprichos, El mal poema (estudio y edición critica) (1997), que fue base para su canónica edición de esas tres obras en el año 2000, y Entre el modernismo y la modernidad: la poesía de Manuel Machado (Alma y Caprichos) (1999). Por su parte, además de la edición citada, son muy interesantes por el material que incorporan las 